\title{
Preparation and Application of Polymer Silicate Phosphate Ferric Sulfate Used in High-Viscosity Oil Refining Wastewater Treatment
}

\author{
Xi CHEN, Xinyang XU, Yindi FAN \\ School of Resources and Civil Engineering, Northeastern University, Shenyang, China \\ E-mail: Chenxineu@mail.neu.edu.cn \\ Received March 31, 2009; revised May 18, 2009; accepted May 25, 2009
}

\begin{abstract}
A new kind of flocculants, named Polymer Silicate Phosphate Ferric Sulfate(PSPFS), was synthesized by ferrous sulfate used as the main material and activated silicic acid as additive. In this paper, High-Viscosity Oil Refining wastewater from Liaohe Petrochemical Corporation was the treatment object. Overall, the influencing factors and synthesis technology conditions of PSPFS were determined by experiments. First of all, the conditions of influencing factors were showed as follows: the mass percent concentration of ferrous sulfate $55 \%$,concentration of sodium silicate $15 \%$, the molar ratio of ferrous sulfate and hydrogen peroxide 1.2: 1 , oxidation temperature 40 degree Celsius, oxidation time 4 hours, polymerization temperature 60 degree Celsius and polymerization time 2 hours. Secondly, the optimal ratios of components were determined by uniform design method. The molar ratio of $\mathrm{Fe} / \mathrm{Si}$ is 5.0: 1 , Fe/H2SO4 is 3.2: 1, and Fe/P is 18.0: 1 . At last, the optimal experimental condition was determined as follows: the dosing quantity $200 \mathrm{mg} / \mathrm{L}, \mathrm{pH}$ value 5.5 9, temperature $25 \sim 45^{\circ} \mathrm{C}$, stirring time $2 \mathrm{~min}$, and standing time $3 \mathrm{~min}$, according to the result of flocculation experiments with PSPFS. Besides, the result of the comparative experiments showed that the efficiency of PSPFS was much better than the reference flocculants.
\end{abstract}

Keywords: Polymer Silicate Phosphate Ferric Sulfate, Flocculant, Preparation, High-Viscosity Oil Refining Wastewater

\section{Introduction}

High-Viscosity Oil is abundant in China and has an annual output of more than 30 million ton. It makes an essential role in the petrolic exploration and development. In the exploitation process, High-Viscosity Oil will generate a large number of mining liquid which is consisted of crude oil, silt and water. The ratio of oil/ water is highly changeable, since it depends on many factors, such as oil reservoir geology, the service life of oil wells, and the relationship between steam and oil wells and so on. In most cases, the volume of water in mining liquid is twice to 20 times than that of oil, for about four times usually [1]. The High-Viscosity Oil Refining composition is extremely complex. And how to disposal such kind of wastewater becomes the important factor which restricts the development of High-Viscosity Oil Refining.
Therefore, researches on the treatment of High-Viscosity Oil Refining wastewater have essential theoretical and practical significance. There are many kinds of methods to treat High-Viscosity Oil Refining wastewater, such as physical methods, physical-chemistry methods, biochemistry methods [2-4] and so on. Flocculation is a major method. Especially, silicon polymers have caused widespread concern [5-7], due to the new flocculants with high-strength polymer capacity in the physical and chemical processing.

\section{Experimental Medicaments and Materials}

\subsection{Experimental Medicaments}

The major experimental medicaments include: $\mathrm{FeSO}_{4} \cdot 7 \mathrm{H}_{2} \mathrm{O}, \mathrm{Na}_{2} \mathrm{SiO}_{3} \cdot 9 \mathrm{H}_{2} \mathrm{O}, \mathrm{H}_{2} \mathrm{SO}_{4}, \mathrm{H}_{2} \mathrm{O}_{2}$, phosphating 
Table 1.The water quality index of water sample.

\begin{tabular}{cccc}
\hline Oil & sulfur & hydroxybenzene & COD \\
\hline 1305 & 21.34 & 59.24 & 2865 \\
\hline
\end{tabular}

stabilizer, petroleum ether, anhydrous sodium sulfate, $\mathrm{NaOH}$ and so on.

\subsection{Equipments}

The major equipments include: 752 spectrophotometer, magnetic heating stirrer, pHS-2 acidometer, electronic analytical balance, vacuum pump, glass funnel, vacuum filter bottles, colorimetric tube, volumetric flask, burette, and so on.

\subsection{Test Water Samples}

The test water samples from wastewater treatment plant of the Liaohe Petrochemical Company. They were mainly originated from the crude oil dehydration, various refineries, coking plant and petrochemical installations drainage and a small amount of sewage. Water quality $(\mathrm{pH}=8.24)$ is shown in Table. 1 .

\subsection{Testing Methods}

The oil content in samples was tested by the 752 spectrophotometer.

\section{The Preparation of Polymer Silicate Phosphate Ferric Sulfate}

\subsection{The Preparation Principle}

In acid conditions, $\mathrm{FeSO}_{4}$ was oxidized to $\mathrm{Fe}_{2}\left(\mathrm{SO}_{4}\right)_{3}$, then hydrolysis, polymerization reaction of red-brown polyferric sulfate. The main reaction is as follows:

Oxidation:

$$
2 \mathrm{FeSO}_{4}+\mathrm{H}_{2} \mathrm{O}_{2}+\mathrm{H}_{2} \mathrm{SO}_{4} \rightarrow \mathrm{Fe}_{2}\left(\mathrm{SO}_{4}\right)_{3}+\mathrm{H}_{2} \mathrm{O}
$$

Hydrolysis:

$$
\mathrm{Fe}_{2}\left(\mathrm{SO}_{4}\right)_{3}+n \mathrm{H}_{2} \mathrm{O} \rightarrow \mathrm{Fe}_{2}(\mathrm{OH})_{n}\left(\mathrm{SO}_{4}\right)_{3-\frac{n}{2}}+\frac{n}{2} \mathrm{H}_{2} \mathrm{SO}_{4}
$$

Polymerization:

$$
m\left[\mathrm{Fe}_{2}(\mathrm{OH})_{n}\left(\mathrm{SO}_{4}\right)_{3-\frac{n}{2}}\right] \rightarrow\left[\mathrm{Fe}_{2}(\mathrm{OH})_{n}\left(\mathrm{SO}_{4}\right)_{3-\frac{n}{2}}\right]_{m}
$$

In the polymerization process, activated phosphate and silicate are added step-by-step, and copolymerized with the polyferric sulfate. In this way, we can get the PSPFS. The essence is that coordinated water molecules in hydrated cation dissociated $\mathrm{H}^{+}$step by step in the process of forming covalent complexes by ferric ions. With the $\mathrm{H}^{+}$ dissociation, it forms a series of hydroxyl complexes.
Mononuclear complexes can generate hydroxyl polynuclear complexes in the process of hydroxyl connection. In general, it can be easier to form hydroxyl complexes when the iron concentration is larger. In the effect of high temperatures, long-term aging or (and) $\mathrm{pH}$, the hydroxyl connected complexes can be transformed into oxygen connected complexes. There are two ways to form these complexes. One is that the irreversible $\mathrm{M}-\mathrm{O}-\mathrm{M}$ bonds are formed by eliminating monomolecular water between two adjacent hydroxyl bridges. The other is formed by dehydrogenation from hydroxyl. Sillen has presented the "root + section" hypothesis in order to illustrate the formation mechanism of multi-core hydroxyl connection complexes. He said that the $\mathrm{M}(\mathrm{OH}){ }_{\mathrm{t}}{ }^{(\mathrm{n}-\mathrm{t})}{ }^{+}$is added to the cation or cation groups gradually as chain section in the hydrolysis as shown in Figure 1.

\subsection{The Synthesis of Polymer Silicate Phosphate Ferric Sulfate}

We added some concentrated sulfuric acid in a certain quantity concentration of $\mathrm{FeSO}_{4} \cdot 7 \mathrm{H}_{2} \mathrm{O}$ solution, and got Solution 1. Then we dissolved different quantities of $\mathrm{Na}_{2} \mathrm{SiO}_{3} \cdot 9 \mathrm{H}_{2} \mathrm{O}$ in $100 \mathrm{ml}$ water, added appropriate quantity of concentrated sulfuric acid and got Solution 2 after activation. At last, we mixed the two solutions, and added phosphate stabilizing agent and $30 \% \mathrm{H}_{2} \mathrm{O}_{2}$ in order to oxidize $\mathrm{Fe}^{2+}$ into $\mathrm{Fe}^{3+}$. We got the solid product, after baking the product, reddish-brown viscous liquid, which was generated from polymerizing reaction in certain temperature.

The process is shown in the Figure 2.

\subsection{Determination of the Synthesis Conditions of Polymer Silicate Phosphate Ferric Sulfate}

\subsubsection{The Concentration of $\mathrm{FeSO}_{4}$}

On one hand, the $\mathrm{Fe}^{2+}$ and oxidated $\mathrm{Fe}^{3+}$ increase as the increasing of the concentration of $\mathrm{FeSO}_{4}$, which has promoted the polymerization reaction. On the other hand, the product stability and effective components will decline, because the generation probability will increase, which of hydroxyl complexes to precipitate alkaline $\mathrm{Fe}_{2}\left(\mathrm{SO}_{4}\right)_{3}$ in the hydrolysis process. In order to reduce sedimentation, it needs to increase the acidity of the solution. But it will lead to the descent of product basicity and go against to improve the products' overall quality. Consequently, it doesn't mean that the higher iron content, the better the effect of synthesis. If the iron concentration reaches the designed target, the major measure to improve product quality is to enhance its basicity. Considered literatures and feasibility of tests, the concentration of $\mathrm{FeSO}_{4} \cdot 7 \mathrm{H}_{2} \mathrm{O}$ is $55 \%$ (mass percentage) in this experiment.

\subsubsection{The Dosage of $\mathrm{H}_{2} \mathrm{O}_{2}$ and the Temperature}

We used $\mathrm{H}_{2} \mathrm{O}_{2}$ as the oxidant in our experiment. The dosage of $\mathrm{H}_{2} \mathrm{O}_{2}$ not only determines whether $\mathrm{Fe}^{2+}$ can be 


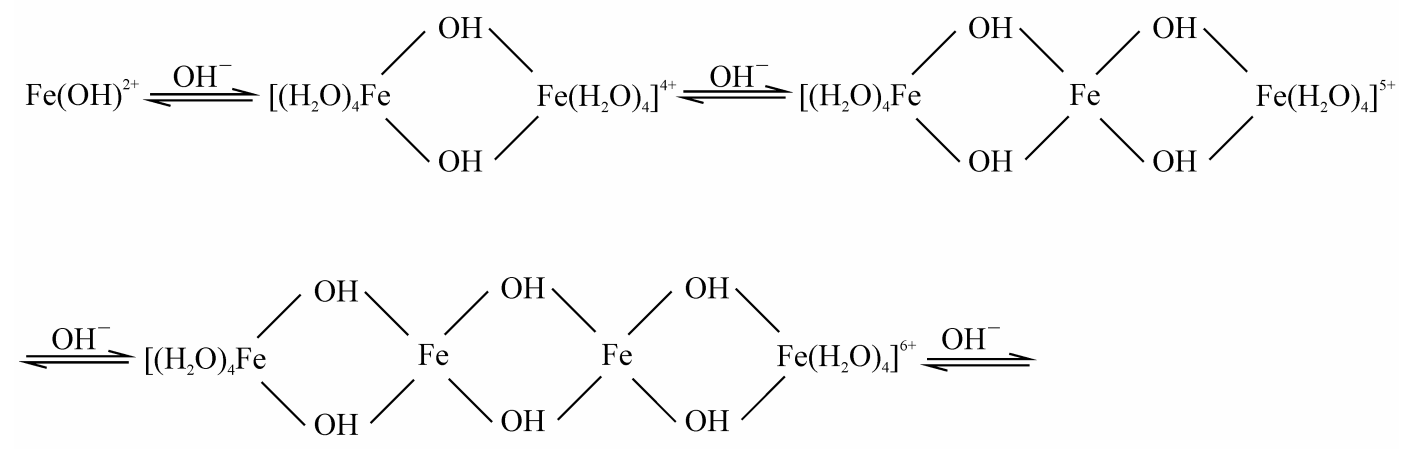

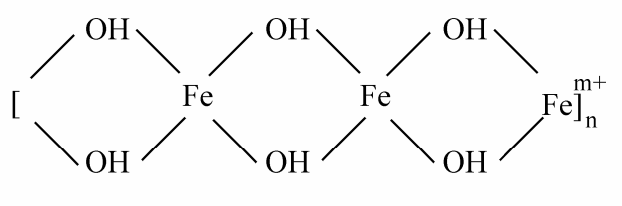

Figure 1. Hydrolytic-polymeric process of $\mathrm{Fe}^{3+}$.

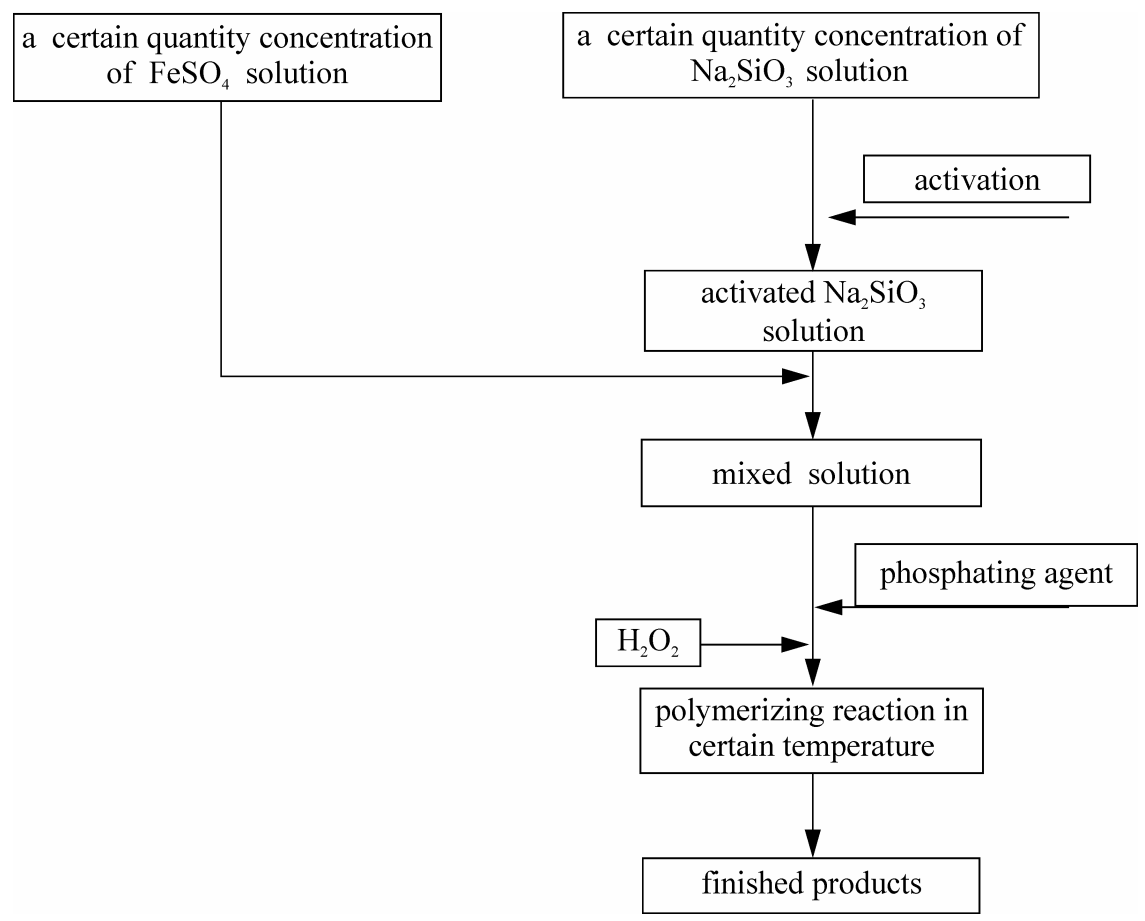

Figure 2. Preparation technology of polymeric phosphate ferric sulfate silicate.

transformed into $\mathrm{Fe}^{3+}$ completely, but also infects the quality of the final products. If the dosage of $\mathrm{H}_{2} \mathrm{O}_{2}$ is not enough, the quality of the final products will reduce as the effective components decline. It shows that, $\mathrm{Fe}^{2+}$ can not be detected when molar ratio of $\mathrm{H}_{2} \mathrm{O}_{2} / \mathrm{Fe}^{2+}$ was 1.2:1 in our experiment. As a result, it is determined that its ratio is 1.2:1.

It is exothermic reaction when $\mathrm{Fe}^{2+}$ transformed into $\mathrm{Fe}^{3+}$, therefore, it increases the temperature of the reac- tion system, and accelerates the decomposition of hydrogen peroxide. We used normal temperature waterbath to control the temperature in the experiment.

\subsubsection{The Concentration of Sodium Silicate Solution and the Dosage of Activated Acid}

According to the experiments, we found that it could cause the experimental failure when the concentration of sodium silicate was more than $20.0 \%$. In the activation 
process, a few light blue floccules appeared, and formed gel immediately. Therefore, it must be controlled that the concentration of sodium silicate is below $15 \%$ in the experimental process. Also, the dosage of activated acid influenced the polymerization of Polymer Silicate Phosphate Ferric Sulfate in the activation process. The experiment shows that we can get the uniform and stable activated silicic acid, if the concentration of $\mathrm{H}_{2} \mathrm{SO}_{4}$ was adjusted to $2 \%$. Therefore, it is determined that the concentration of $\mathrm{H}_{2} \mathrm{SO}_{4}$ is $2 \%$ in our study.

\subsubsection{Temperature and Time of Polymerization}

Both temperature and time are important factors which influence the product quality, and directly determine the production cycle and applied efficiency of products. If polymerization temperature was too high, and polymerization time was too long, it would enhance water evaporation intensively, decline product stability, generate turbidity and precipitated, and cause long production period. In contrary, if the temperature was low, and time was short, it would lead to incomplete polymerization and inefficient purification effect. According to the experiment, the optimal temperature of polymerization is $60^{\circ} \mathrm{C}$, while the optimal time of that is 2 hours.

\subsection{The Optimal Ratio of Components in the Synthesis Process of Polymer Silicate Phosphate Ferric Sulfate}

According to the analysis above, it is clear to see that the ratio of ferric ion and sulfuric acid, ferric ion and silicate, and ferric ion and phosphate radical are determining factors of PSPFS's synthesis and product quality. In the synthesis process, $\mathrm{pH}$ value can be controlled by the dosage quantity of the concentrated sulfuric acid. And the ratio of ferric ion and silicate, and that of ferric ion and phosphate radical can be controlled by the dosage quantity of phosphoric acid and sodium silicate in reaction. The three factors have mutual restriction and affect the ultimate effect separately; therefore, the effects of the other two factors should be considered when one of the factors is regulated. We performed the uniform design experiment to confirm the optimal ratio of components of PSPFS which could be suitable for High-Viscosity Oil Refining wastewater treatment. The schedule of experimental elements is shown in Table. 2.

In order to research the flocculation effect of PSPFS which was synthesized in different conditions, we used flocculation methods to treat High-Viscosity Oil Refining Wastewater. And the dosing quantity of $\mathrm{FeSO}_{4}$ was $200 \mathrm{mg} / \mathrm{L}$. The results and phenomena are shown in the Table 3.

On the basis of multiple regression analysis of experimental results [8], we determined the optimal ratio of components in the synthesis process of PSPFS as is shown in the Table4 after considering product stability, treatment efficiency and so on.

\section{The Application of PSPFS in the Flocculation Treatment of High-Viscosity Oil Refining Wastewater}

\subsection{Determination of the Optimal Experimental Conditions}

In order to optimize the experimental conditions, we performed the experiments to treat real wastewater from High-Viscosity Oil Refining Corporation.

Table 2. Schedule of experimental element.

\begin{tabular}{cccc}
\hline $\begin{array}{c}\text { Experimental } \\
\text { serial number }\end{array}$ & $\begin{array}{c}\text { Mol ratio of ferric ion and } \\
\text { silicate (X1) }\end{array}$ & $\begin{array}{c}\text { Mol ratio of ferric ion and } \\
\text { sulfuric acid (X2) }\end{array}$ & $\begin{array}{c}\text { Mol ratio of ferric ion and } \\
\text { phosphate }(\text { X3) }\end{array}$ \\
\hline 1 & 4.46 & 1.95 & 5.70 \\
2 & 2.90 & 1.21 & 3.25 \\
3 & 2.26 & 1.49 & 4.32 \\
4 & 11.23 & 2.17 & 13.24 \\
5 & 5.21 & 1.41 & 5.66 \\
6 & 3.57 & 2.17 & 21.97 \\
8 & 2.81 & 2.33 & 7.35 \\
10 & 10.37 & 1.58 & 44.26 \\
\hline
\end{tabular}


Table 3. The experimental result and phenomenon of each level.

\begin{tabular}{|c|c|c|c|}
\hline $\begin{array}{l}\text { The level of the } \\
\text { serial number }\end{array}$ & $\begin{array}{c}\text { Average } \\
\text { absorbance A }\end{array}$ & $\begin{array}{l}\text { Oil content } \\
(\mathrm{mg} / \mathrm{L})\end{array}$ & Experimental phenomena \\
\hline 1 & 0.429 & 59 & $\begin{array}{l}\text { Synthetic products were steady; sedimentation was not apparent within } 10 \\
\text { days; there were sank floccules after the treatment. }\end{array}$ \\
\hline 2 & 0.744 & 105 & $\begin{array}{l}\text { There were a small amount of floccules in oxidation process. After oxida- } \\
\text { tion, the floccules disappeared. The stability of synthetic products was poor } \\
\text { and a few precipitates appeared after } 24 \text { hours. There were sunk floccules } \\
\text { after the treatment. }\end{array}$ \\
\hline 3 & 0.503 & 70 & $\begin{array}{l}\text { Synthetic products were steady; sedimentation was not apparent within } 10 \\
\text { days; there were sank floccules after the treatment. }\end{array}$ \\
\hline 4 & 0.377 & 52 & $\begin{array}{l}\text { Synthetic products were steady; sedimentation was not apparent within } 10 \\
\text { days; there were sank floccules after the treatment. }\end{array}$ \\
\hline 5 & 0.343 & 47 & $\begin{array}{l}\text { The stability of synthetic products was poor; gel phenomenon appeared after } \\
24 \text { hours; there were sunk floccules after the treatment. }\end{array}$ \\
\hline 6 & 0.433 & 60 & $\begin{array}{l}\text { The stability of synthetic products was poor; gel phenomenon appeared after } \\
24 \text { hours; there were sank floccules after the treatment. }\end{array}$ \\
\hline 7 & 0.381 & 52 & $\begin{array}{l}\text { Synthetic products were steady; sedimentation was not apparent within } 10 \\
\text { days; there were floated floccules after the treatment. }\end{array}$ \\
\hline 8 & 0.345 & 47 & $\begin{array}{l}\text { Synthetic products were unsteady; partial gel appeared after } 24 \text { hours; there } \\
\text { were sank floccules after the treatment. }\end{array}$ \\
\hline 9 & 0.367 & 50 & $\begin{array}{l}\text { Synthetic products were unsteady; a small amount of } \mathrm{Fe}(\mathrm{OH})_{3} \text { precipitated; } \\
\text { there were sunk floccules after the treatment. }\end{array}$ \\
\hline 10 & 0.247 & 33 & $\begin{array}{l}\text { Synthetic products were steady; sedimentation was not apparent within } 10 \\
\text { days; there were sank floccules after the treatment. }\end{array}$ \\
\hline
\end{tabular}

Table 4. The optimal ingredient of composition.

\begin{tabular}{ccc}
\hline $\begin{array}{c}\text { Mol ratio of } \\
\text { ferric ion to } \\
\text { silicate }\end{array}$ & $\begin{array}{c}\text { Mol ratio of } \\
\text { ferric ion to } \\
\text { sulfuric acid }\end{array}$ & $\begin{array}{c}\text { Mol ratio of ferric } \\
\text { ion to phosphate }\end{array}$ \\
\hline 5.0 & 3.2 & 18.0 \\
\hline
\end{tabular}

\subsubsection{Determination of Flocculant Dosage} The dosage not only impacts the oil removal efficiency, but also the cost of medicament. The result of different dosage is shown in Figure 3.

As shown in Figure 3, the optimal dosage is in the range of $200 \sim 250 \mathrm{mg} / \mathrm{L}$. Given the economic efficiency, $200 \mathrm{mg} / \mathrm{L}$ is the most suitable.

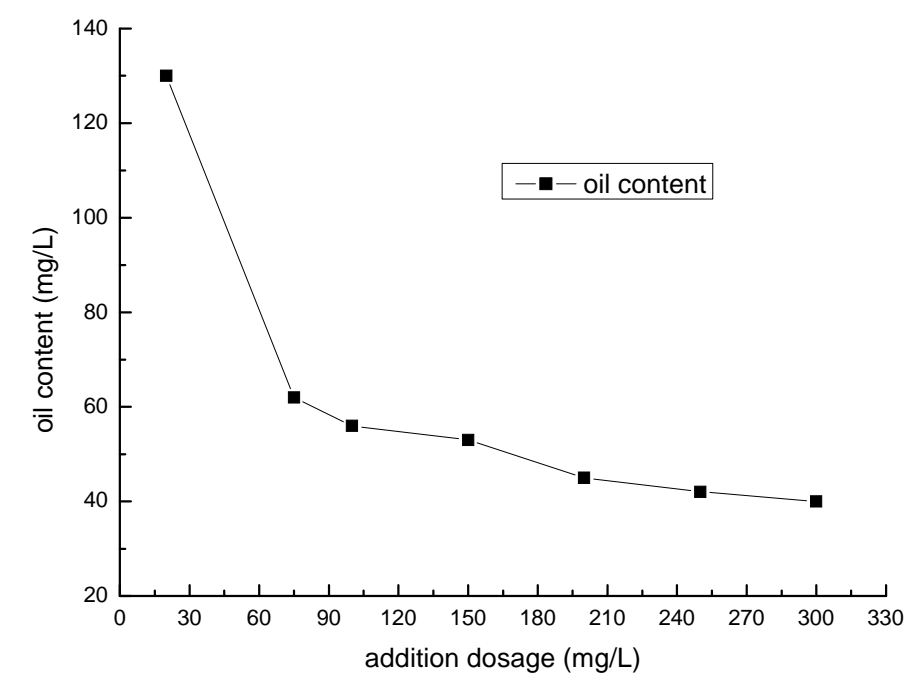

Figure 3. Effect of flocculant addition on removal efficiency of oil. 


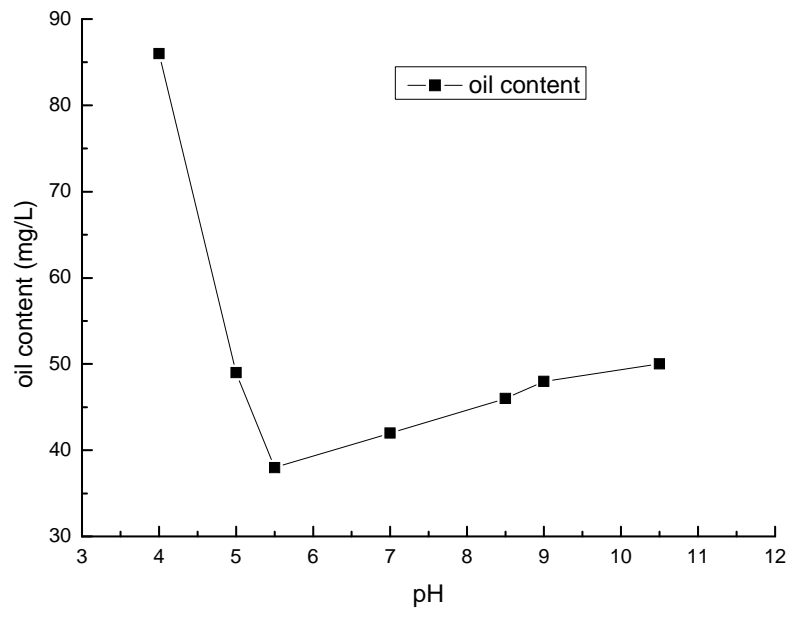

Figure 4. Effect of pH on removal efficiency of oil.

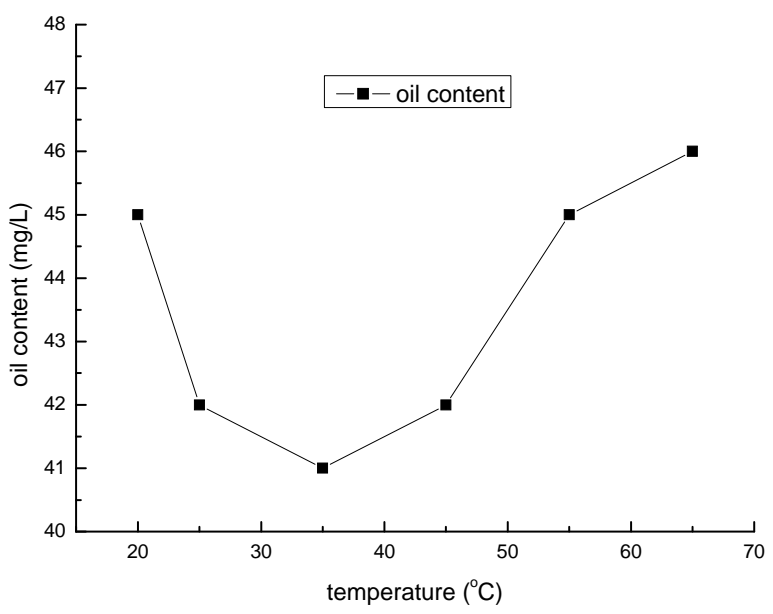

Figure 5. Effect of temperature on removal efficiency of oil.

\subsubsection{The Determination of $\mathrm{pH}$}

In order to research the effect of $\mathrm{pH}$ value on the flocculation experiment, we added PSPFS with dosage quantity of $200 \mathrm{mg} / \mathrm{L}$ in the High-Viscosity Oil Refining Wastewater with different $\mathrm{pH}$ value. The result is shown in Figure 4.

From Figure 4, the optimal $\mathrm{pH}$ value is in the range of $5.5 \sim 9$. It is clear to see that the removal efficiency was low if the wastewater was strong acid or weakly-alkaline. There are two reasons. One is that a great deal of $\mathrm{H}^{+}$ generated in the wastewater, and prevented the polynuclear hydroxo iron from generating in strong acid condition. The other reason is that a mass of $\mathrm{OH}^{-}$changed polynuclear hydroxo iron into $\mathrm{Fe}(\mathrm{OH})_{3}$ which precipitated from the water in alkaline condition. However, the effect in alkaline was small than that in strong acid. It is due to that the silicon and phosphor in PSPFS displayed buffer action. After investigating the monitoring data in Liaohe Petrochemical Corporation, we found that the $\mathrm{pH}$ value of wastewater was in the range of $5 \sim 10$, and its average value was 8.0. Therefore, it has on need to regulate $\mathrm{pH}$ value in practical operation.

\subsubsection{The Determination of Temperature}

Temperature is another condition that will impact the flocculation efficiency. As a result, we preformed a set of experiment with different temperatures of samples. In the experiment, the dosage was $200 \mathrm{mg} / \mathrm{L}$, and $\mathrm{pH}$ value was 5.5. The result is shown in Figure 5.

It is shown in Figure 5 that the optimal temperature is between $25 \sim 45^{\circ} \mathrm{C}$. It will reduce the effect of flocculation if the temperature is too high or too low. Virtually, if the temperature is low, not only the speed of Brownian motion will decline, but also the collision probability between flocculants and oil molecules will decrease. In contrary, high temperature will accelerate the reaction rate, generate small flocs, enhance the hydration of the small flocs, and slow down their settling velocity. Overall, excessive water temperature is adverse to flocculation. In practical operation, we needn't regulate the temperature of the sewage of Liaohe Petrochemical Company, which is in the optimal temperature range.

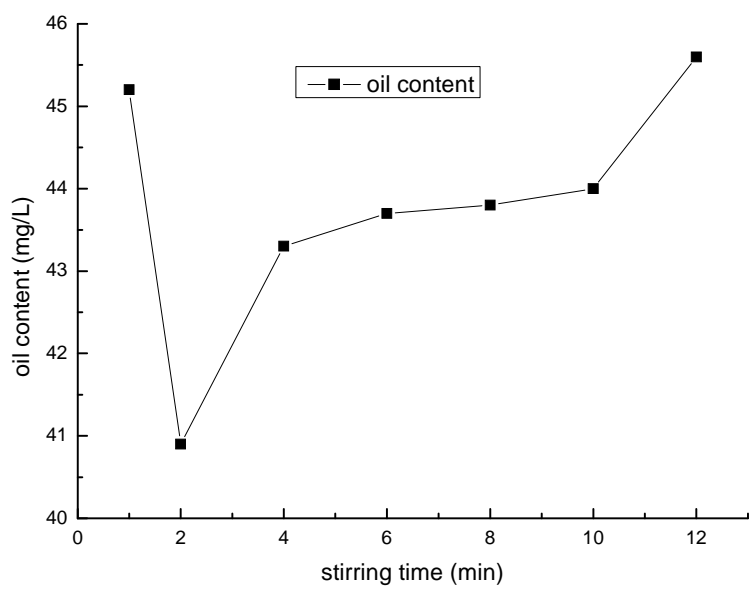

Figure 6. Effect of stirring time on removal efficiency of oil.

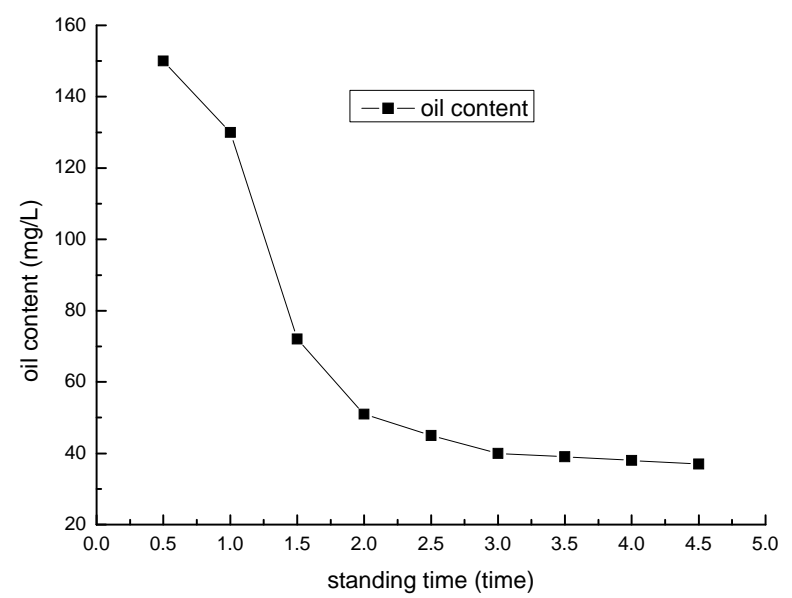

Figure 7. Effect of standing time on removal efficiency of oil. 


\subsubsection{The Determination of Stirringing Time}

We performed the experiment with different stirring time of wastewater. The result is shown in Figure 6 .

As it is shown in Figure 6, when the stirring time is 2 minutes, the removal efficiency of oil is highest of all. If the time is too long or too short, the removal efficiency is low. One of the main reasons is that the flocculants and wastewater aren't mixed intensively, and the hydrolysis is not complete in short stirring time. The other reason is that stirring for a long time will destruct the flocs, make saturation absorption flocs desorpt easily, and be disbenefit to the conglomeration and accretion of small flocs. Overall, according to the effect of stirring time on the removal efficiency, the optimal stirring time is two minutes.

\subsubsection{The Determination of Standing Time}

We determined oil content of the supernatant liquid after different standing time. The result is shown in Figure 7.

In Figure 7, it is shown that the optimal standing time is $3 \mathrm{~min}$. When the standing time is less than $2 \mathrm{~min}$, the flocculation do not finish and the flocs suspend in the liquor. In this situation, the oil content is high. In contrary, when the standing time is over $3 \mathrm{~min}$, the flocs generate in the liquor almost precipitated and flocculation are finished. In this situation, the oil content drops to about $30 \mathrm{mg} / \mathrm{L}$. As the increase of the standing time, the oil content drops continually, but inconspicuously. Overall, according to the economic benefits and practical requirements, the optimal standing time is $3 \mathrm{~min}$.

\subsection{The Comparison of PSPFS and Reference Flocculants Used in Practical Operation}

In order to investigate more about the flocculation effect of PSPFS, we performed a great number of repeated experiments in the optimal condition of PSPFS's flocculation. We compared the removal efficiencies of oil, COD, sulfur and phenol between PSPFS and reference flocculants in the wastewater treatment plant of Liaohe Petrochemical Corporation. The results are shown in Figure 8-11 separately.

In Figure 8-11, it is clear to see that the removal efficiency of PSPFS is much better than the reference flocculants used in wastewater plant. In Table.5, it shows the average efficiencies of the two flocculants to removal the four pollutants.

\section{Conclusion}

1) This paper analyzed the effect of PSPFS's synthesis factors on output quality. According to our experiment, it is determined as follows: mass percent concentration of ferrous sulfate $55 \%$, concentration of sodium silicate $15 \%$, mol ratio of ferrous sulfate and hydrogen peroxide 1.2:1, oxidation temperature 40 degree Celsius, oxidation

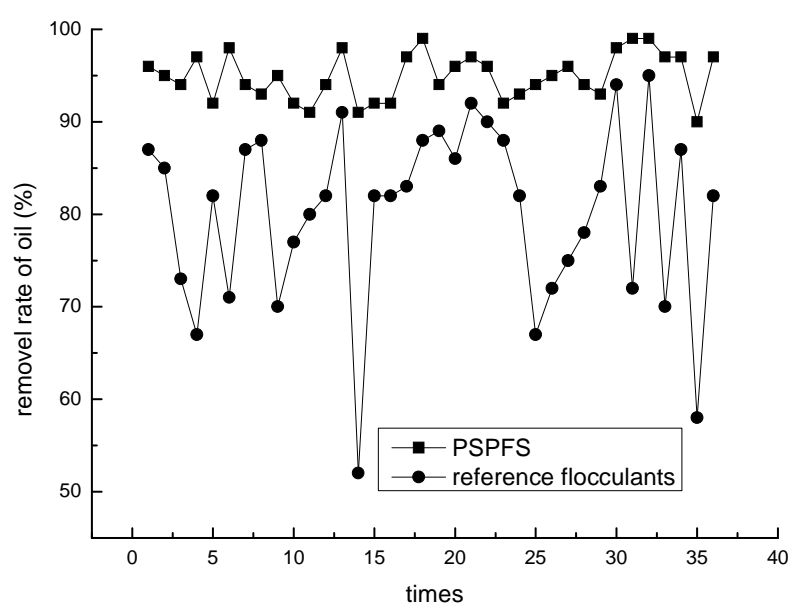

Figure 8. The comparison of oil removal efficiency.

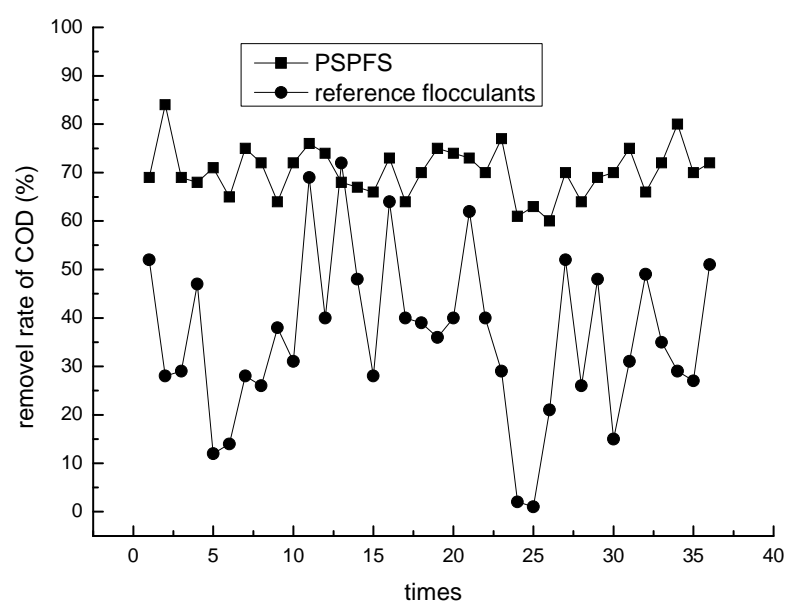

Figure 9. The comparison of COD removal efficiency.

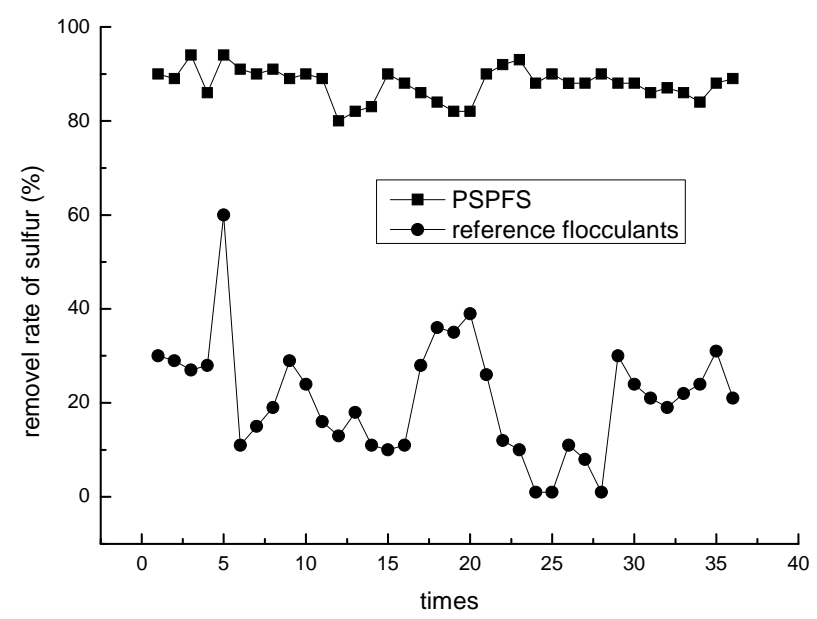

Figure 10. The comparison of sulfur ion removal efficiency.

time 4 hours, polymerization temperature 60 degree Celsius, and polymerization time 2 hours. 


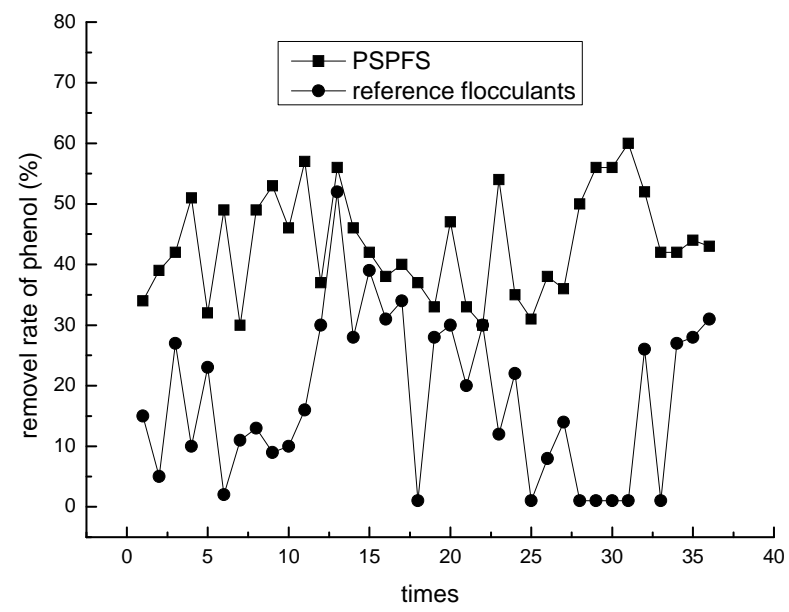

Figure 11. The comparison of phenol removal efficiency.

2) According to equal designed experiment, we obtained the oil removal efficiencies of PSPFS which was synthesized in different conditions. Considered comprehensively the factors, such as stability, removal efficiency and so on, the optimal ratios of components of PSPFS were determined as follows: molar ratio of $\mathrm{Fe} / \mathrm{Si}$ 5.0:1, $\mathrm{Fe} / \mathrm{H}_{2} \mathrm{SO}_{4}$ 3.2:1, and $\mathrm{Fe} / \mathrm{P}$ 18.0:1.

3) The PSPFS was used to treat actual High-Viscosity Oil Refining wastewater of Liaohe Petrochemical Corporation. The result shows that its optimal dosage quantity is $200 \mathrm{mg} / \mathrm{l}$, pH value is between 5.5 and 9, temperature is between 25 and $45^{\circ} \mathrm{C}$, stirring time is $2 \mathrm{~min}$ and standing time is $3 \mathrm{~min}$.

4) A set of contrast experiments was performed to compare PSPFS and flocculants used in wastewater treatment of Liaohe Petrochemical Corporation. The result shows that the treatment efficiency of PSPFS is higher than those of the reference flocculants. The average removal efficiency of oil was $94.1 \%$, COD was 69.4 $\%$, sulfide was $88.9 \%$ and volatile phenol was $43.5 \%$, when PSPFS was used to treat the wastewater. And the average removal efficiency of oil was $80.5 \%$, COD was $35.8 \%$, sulfide was $21.1 \%$, and volatile phenol was $17.3 \%$, when reference flocculants was used. In addition, the treatment efficiency of PSPFS was more stabile than that of the reference flocculants.

\section{References}

[1] R. Zhang, "The technology of heavy oil thermal recovery,” Beijing: Petroleum industry press, 1999.

[2] H. Y. Hao, ZW Cui, and H. Y. Hao, "Studies and applications of flocculants in water treatment,” Journal of North China Institute of Technology, No. 2, pp. 137-140, 1999.

[3] X. Y. Xu and N. N Gu, "Screening and domestication of microorganism used in oil contaminated wastewater remediation [J]," Journal of Northeastern University: Natural Science, No. 5, pp. 721-724, 2007.

[4] X. Y. Xu and N. N. Gu, "Chemical embedding immobilization technique of microorganism used in oil contaminated wastewater remediation,” Transaction of NEU, No. 9, pp. 1329-1332, 2007.

[5] B. Y. Gao, H. H. Hahn, and E. Hoffmann. "Evaluation of aluminum-silicate polymer composite as a coagulant for water treatment," Water Research, Vol. 36, No. 14, pp. 3573-3581, 2002.

[6] A. K. Arnold-Smith and R. M. Christie, "Polyaluminum silicate sulfate-A New coagulant for potable and wastewater treatment," Proc of the 5th Gothenburg Symposium, France, 1992.

[7] B. Y. Gao, Q. Y. Yue, and B. J. Wang, "Poly-aluminum-silicate-chloride (PASiC)-A new type of composite inorganic polymer coagulant,” Colloids and Surfaces A: PHysicochemical and Engineering Aspects, Vol. 229, No. 1-3, pp. 121-127, 2003.

[8] L. J. Li, "Preparation of polymer silicate phosphate ferrous sulfate and its applicant on high-viscosity oil refining wastewater treatment [D],” Northeastern University, 2004. 